\title{
Longitudinal Faculty Study Groups: A Model For Developing Comprehensive Teacher Preparation Programs
}

Leslie L. Griffin, Delta State University, USA

Cheryl J. Cummins, Delta State University, USA

\begin{abstract}
Teacher preparation programs nationwide struggle to meet rigorous national standards, particularly as they relate to the assessment standard of the National Council of Accreditation of Teacher Education (NCATE). There are many issues which make decisions about program improvement complex, often confusing and frustrating faculty. These include the challenge of orchestrating interdisciplinary studies through multiple college/university organizational structures, meeting the specialized requirements of competing professional organizations, communicating and coordinating these efforts with partner P-12 schools, and systematically acquiring data on multiple assessments to make informed decisions about program improvement. Only when faculty and program planners come to grips with the organic nature of the process does it begin to crystallize and fall into place. The realization that this is an evolutionary process and one that cannot be forced is fundamental to healthy and seamless program development. The authors propose to share a study process spanning three years and in continuance that has allowed faculty at a regional university to develop and monitor the teacher preparation program through the reasoned and studied involvement of each faculty member.
\end{abstract}

Keywords: longitudinal faculty study groups, teacher preparation programs, program development, goal-oriented study sessions, NCATE assessment standards, collaboration

\section{INTRODUCTION}

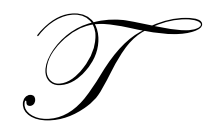

he gauntlet has been thrown down before teacher preparation programs: develop and deliver high quality teacher preparation programs that prepare students for performance capability (Lang \& Evans, 2006; Levine, 2006; U.S. Department of Education, 2006). Maxie (2001) stresses the need for the "development of standards for teacher preparation; the crafting of a teaching performance assessment for preservice candidates; and, the building of a flexible teaching credential architecture" (p. 115). Her description of blended teacher education programs which incorporate early field experience components and the integration of the professional knowledge base with subject matter preparation sets well with the National Council for Accreditation of Teacher Education (NCATE) Standards emphasizing content knowledge, pedagogical content knowledge, and professional and pedagogical content knowledge, skills, and dispositions (NCATE, 2002). Maxie further establishes the historical context for the shift in teacher education programs from serving as dispensers of theory to members of collaborative networks focused on the total professional preparation of the teacher candidate. She describes a continuum beginning in the 1970s, during which there was a disconnect between teacher preparation programs and the realities of the classroom. A shift occurred during the 1980s and 1990s, during which the complexities of teacher development and field experiences, the need for reflective inquiry, and the collaborative nature of the teacher preparation process were recognized (2001). Yet, Lang and Evans (2006) caution that classic educators need not be relegated to the past. Their work provides scientific basis for blending theory and practice in teacher education. 
Murphy and Lick (2005), noted for their work in pioneering faculty study groups in schools, assert that leading faculty in new ways requires program planners/leaders to establish an environment in which faculty can feel supported and safe in expressing ideas while aggressively seeking solutions to problems. They also identify student learning as the target for such study groups. Wildman, Hable, Preston, and Magliaro (2000) acknowledge that faculty study groups have for some time now been identified as viable means by which to discuss problems, as well as engage in meaningful programming, yet they identify that it is a challenge to implement and sustain such at universities where faculty members often work in a more independent and isolated fashion. Through their work, a step-by-step process for faculty study groups emerged. Experience has taught this group that successful faculty study groups emerge around an organizational structure hinging on common meeting times/purposes and a leader who supports the group and facilitates its work. Burton (1997), in reporting on the efforts of social work faculty at Andrews University, points out that the "success of long-term faculty development initiatives is dependent on the success of the faculty study groups" (p. 10).

Teacher education faculties benefit from such structures when faced with the task of considering myriad factors associated with student achievement in P-12 schools today and the associated accountability that is tied directly to their programs. Without a reasoned approach to studying problems, reflecting upon practice, and open dialogue about ways to address problems, an unscientific, haphazard approach to problem solving might result. Admittedly a time-consuming process, and one that takes years to institutionalize, Lick (2000) proposes that the positives associated with it are numerous, with schools representing learning organizations in which faculty build their capacity to create desired results, where innovative thinking and the ability to learn together is coveted. Not the least of the benefits is the opportunity for increased attention to content requirements in teacher preparation programs, as identified by the Standards-Based Teacher Education Project (STEP) initiative (Garvin, 2003).

\section{IMPLEMENTATION OF LONGITUDINAL FACULTY STUDY GROUP}

While the faculty body of the Elementary Education Department at Delta State University had historically been a very cohesive group of professionals who met regularly and worked collaboratively toward program goals, several factors came to bear upon their decision to institute more focused and goal-oriented study sessions. Based on careful study of the National Council for Accreditation of Teacher Education (NCATE) Standards and with consideration of the other influences upon the curriculum associated with the elementary education degree program, the faculty body (comprised of seven members) decided in the fall of 2003 to hold an initial retreat to develop a plan of action for the review of the entire elementary education curriculum. On October 20, 2003, the group met to take stock. Uppermost in the group's mind was to remain authentic to the region and teacher candidates being served, which aligns with the University's mission to be an outstanding regional university. As each external influence upon the curriculum was brought forward, the group returned to the question, "What are the implications for the candidates we serve?" Faculty members very much desired to remain true to a program associated with sensible and meaningful goals aimed at producing competent and caring teachers, as opposed to adopting goals and/or methodologies in an effort to "jump on the bandwagon" of the latest reform. Therefore, the faculty spent a major portion of this initial retreat interpreting and analyzing concepts and definitions that related directly to the program's viability. At this juncture, these included attention to the highly qualified status of teachers issuing from No Child Left Behind legislation; the standards of the Association for Childhood Education International (ACEI), the specialized professional association for elementary education; and the standards of the National Council for the Accreditation of Teacher Education (NCATE), through which the College of Education is nationally recognized. Faculty began with analyzing the criteria for highly qualified teaching status put forth by the Mississippi Department of Education in an effort to determine if current program parameters produced candidates with these qualifications. Since the elementary education coordinator had recently attended training offered nationally through NCATE, a logical starting point for analyzing the program in light of professional standards was the dissemination and explanation of both the NCATE Standards and the related glossary, as well as a review of ACEI Standards and the overall program review process. Consensus was drawn from this significant initial meeting around the following:

1) The mandate for a 124-hour curriculum by the Mississippi Institutions of Higher Learning Board rendered it difficult to meet the State's definition for highly qualified status in grades $7-8$. Therefore, the 
certification level being served would need to be studied in greater detail. Major decisions would have to be made in the near future to address this important issue.

2) While the elementary education degree program was inherently sound and met the spirit of the standards, there were several points at which it did so in an informal fashion, thereby necessitating a more tangible and measurable set of outcomes. Areas of particular concern emerged around the manner in which candidates' impact upon P-12 student learning was being addressed and the manner in which experiences cut across all content areas in an integrated fashion.

3) The then-current exit portfolio system, while providing a cogent picture of the emerging teacher professional, did not reliably provide a measure of the degree to which candidates met program goals. Also, debate was held about how prescriptive the portfolio process should be, and a central discussion theme centered on just what purpose the portfolio should serve in accomplishing program outcomes.

4) Additional study should be given the manner in which candidates were assessed across the program, with attention to key transition points.

As a result of the retreat, the faculty body grew in its awareness that the answers to these and related overarching questions would not be answered quickly or easily. Also clear was the fact that the group would have to make a commitment to study together in a focused and ongoing fashion if the program was to continue to be a viable one and if candidates' needs were to be met in the changing context of teacher preparation. Therefore, several norms emerged. First and foremost, members agreed that study would have to take place in a regular and systematic fashion, with all members present. In addition, a commitment to outside reading and study would be essential to accomplishing tasks when the group convened. Coming "cold" to a meeting would not be an option. A notebook was begun so that all members could easily reference the same materials as study and work ensued. From initial discussions among group members, who ranged from 30+ year veterans to those who had been affiliated with the program fewer than 10 years, the following guiding principles emerged, and would prove central to the evolutionary study process of the group.

\section{GUIDING PRINCIPLES FOR FACULTY STUDY GROUP}

1. Study and dialogue engaged in by the group should be reflective of the contextual factors associated with the candidates being served.

2. The dual and complementary roles of conventional wisdom shaped by personal experience and scientific research should be acknowledged.

3. Program decisions issuing from the faculty study group should be data-driven and outcomes-based.

4. The agenda and goals of the faculty study group should be fluid and open, allowing all stakeholders, constituencies, and external influences to have a voice in the evolution of the teacher preparation program at this institution.

These guiding principles support the University's institutional mission, providing an impetus for promoting candidates committed to helping students in the Delta region learn to their maximum potential through the use of appropriate assessment techniques to monitor performance (Delta State University Bulletin, 2007). In addition, they are consistent with the guiding principles associated with the College of Education Conceptual Framework, which focus on the importance of reflection in light of the contextual factors associated with learners and their environment, the interactive and dynamic nature of the relationships within the learning community, and a commitment to lifelong learning. These under girding principles were a major force in aiding the group in prioritizing and focusing its study topics.

\section{PROGRESSION OF THE STUDY GROUP}

In January 2004, the faculty study group invited the College of Education NCATE Coordinator to elaborate upon the accrediting body's standards. Both the critical role of evaluation and the need for standards to be tied to courses and documents that provide evidence for meeting standards were stressed, as well as the fact that NCATE was in the process of streamlining assessment processes was acknowledged. The group remained steadfast in its determination to focus on collecting meaningful and appropriate data, and began to identify how various standards 
were being met through existing practices. At this point, the group had not developed an assessment system, but was indeed taking stock of the status quo and how it did or did not meet the standards. In particular, faculty read articles about portfolios and consulted with experts in the field to determine if the current system, including its process, product, and presentation, was an appropriate capstone assessment through which to assess candidates' proficiencies.

In addition, the faculty began study of a range of assessments currently in place, as well as results from those assessments in order to shape future experiences or amend assessments. For example, the system in place for assessing the dispositions of candidates was reviewed. Faculty found that while it was being applied consistently and covered a range of dispositions relevant to desirable teacher traits, it was somewhat disconnected and in need of amendment. This need led faculty to focus research reading on the assessment of dispositions for reference in future meetings.

A review of the 2001-2002 Annual Performance Review for Teacher Preparation Programs (Mississippi Institutions of Higher Learning) provided data on how well first-year teachers performed in the state on a number of indicators associated with effective teaching. The review led program planners to conclude that while teacher candidates viewed themselves as competent, principals reported lower ratings for these teachers with respect to their ability to work with special needs students, teach beginning reading, manage student behavior, and apply state and federal guidelines for special populations. As a result, on March 5 of that year, program planners initiated a series of seminars aimed at addressing these issues, simultaneously slating these areas for long-term study with an eye on program improvement.

On February 25, 2004, elementary faculty members reviewed the goals of the elementary education program in light of NCATE Standards. Further, faculty addressed a point of confusion identified by teacher candidates. Program goals were aligned with Interstate New Teacher Assessment and Support Consortium (INTASC) Standards, and candidates found having two sets of correlated goals confusing. The faculty reached consensus on eliminating program goals in an effort to streamline, opting to use INTASC Standards as program goals. Further, the faculty identified how each goal was met throughout the program, charting program/course outcomes and assessments with respect to the elements of NCATE Standard I. These would later be reviewed by the entire faculty. Though elementary faculty shared regularly with content area faculty, it was determined that a more systematic study of relevant field experiences and assessment products needed to be engaged in by the elementary faculty.

By March 2004, a grant by the Standards-Based Teacher Education Project (STEP) was in place to allow faculty across all disciplines to meet and study one another's curriculum in an effort to make interdisciplinary connections. These conversations became a focus of the elementary faculty study group. The portfolio process continued review, with program planners examining how the process intersected the program, and coming to the conclusion that the process was not maximizing the desired outcomes, with perhaps the effort associated with the process outweighing its benefits.

\section{ESSENTIAL FEATURES OF THE STUDY GROUP}

More important than the specific decisions being made across this year was the framework that emerged. Faculty members had made these focused faculty study groups a priority, and were beginning to see real dividends. Essential features supported this framework and made it strong, including the following:

1. The elementary education coordinator provided focus and support, arranging for release time and professional development when necessary, so that the group could prioritize and address critical issues armed with the latest research.

2. Meetings were held twice a month with extended retreats held each semester. All faculty members were required to attend.

3. Research readings were provided based on identified needs, and all members shared perspective on these. 
4. Members were encouraged to share narratives of practice, introduced by Jean Lave in the late 1980s. These stories of experiences with candidates in everyday settings provided the conventional wisdom and insight necessary to make practical and wise decisions about the program.

5. Review of NCATE/INTASC/ACEI Standards was continual, until automaticity of recall was reached and their interrelated features were easily seen.

6. Collaborative partnerships were established and experts tapped when necessary. Subgroups were formed and reformed to look in-depth at critical program and assessment features and make reports to the group in an effort to maximize time and resources.

7. Visuals were used across meetings to articulate an emerging assessment framework and keep the picture before the group.

At this point, the faculty study group had form and shape. Over the course of the next two years, faculty would convene regularly, and a rhythm and flow would prevail at each meeting. Studying data became a regular function. The discussion of scientific practices tempered with narratives of practice influenced decisions. Constituencies and stakeholders were engaged in conversation, with faculty members attending national trainings and sharing insights gleaned. Candidates' work and dispositions were reviewed, with each influencing program development. Along the way, a heightened sense of ownership, as well as comradery, cemented the group and gave it authority, substance, and even intellectual pleasure. Agenda items that were once eyed with rue had made the transition to being viewed as purposeful and necessary, not to mention ultimately rewarding.

\section{COLLABORATIVE NATURE OF THE GROUP}

While the collaborative nature of the group itself reached a heightened state, other stakeholders worked through and with the group to influence and improve the elementary education program. Members of the group attended NCATE-sponsored trainings, both at the national and state levels to increase their understanding of the ACEI program review process and the NCATE process in general. Concurrently, members continued to work through the STEP initiative to improve curriculum connections across all disciplines. Faculty from across the disciplines engaged in discussion with elementary education faculty, sharing information about course outcomes, field experiences, and key standards within their disciplines. Higher education faculty from universities and colleges across the state engaged in important study and curriculum development in an effort to ensure that standards were being met consistently. An example of such a collaborative is the Higher Education Literacy Council sponsored by the Mississippi Department of Education. In bringing together representatives from the higher education institutions across the state, a comprehensive early literacy curriculum was developed through the study of research-based findings, relevant standards, and the consensus of the stakeholders. Representatives from the elementary education faculty study group shared this work on a regular basis and disseminated research-based articles for study by group members. Significant revisions were made in the program's reading curriculum as a result of this work. Collaboration has become the hallmark of this group as a result of these initiatives.

\section{CONCLUSION}

The focused faculty study group has entered its fourth year, and is well on its way to becoming institutionalized. At the beginning of each year, faculty members mark their calendars for the year's meetings, with the understanding that additional called meetings may be necessary. Faculty make attendance at these meetings a priority, realizing that substantive issues will be discussed and having learned that there is no substitute for being there in person. The essential features identified previously continue to provide a framework for the group's work. Outcomes of the group's work thus far are substantial. A comprehensive assessment system has emerged that will continue to undergo study. The portfolio process has been transformed and Renaissance Teacher Work Sample Methodology, a comprehensive reflective process that causes candidates to seriously consider seven dimensions of the teaching/learning process in great detail, is now in place. A key feature of the methodology is the use of pre- and post-test data to determine impact on student learning. Candidates report that the methodology "makes sense," contradictory to feedback often received on the previous portfolio process. Therefore, program planners feel quite a sense of accomplishment since a primary goal was to use meaningful and sensible assessments that would truly inform practice. In fact, an eighth dimension has been added to the teacher work sample to allow for 
interdisciplinary connections. A comprehensive system for both teaching and assessing dispositions has been infused throughout the program. Key assessments have been developed throughout the program, and key transition points identified. As a result, follow-up to the program has been strengthened, with faculty now examining ways to provide first-year support to beginning teachers. In order to provide both a rigorous and streamlined program, the curriculum focus has shifted to K-6 certification, with additional requirements for candidates electing to become highly qualified in grades seven and eight. Partnerships with local schools have been enhanced in an effort to marry university instruction with clinical practice. A reading intervention class is now offered onsite at a local elementary school as a pilot. Faculty members, in anticipation of study topics, make suggestions and have assumed various leadership roles in defining the group's focus and purpose. Even as word was received in June, 2007, that the elementary education program was nationally recognized by ACEI, program planners study assessment data with an eye on curriculum improvement and tweaking assessments. The focused faculty study group has proven itself to be truly longitudinal in nature and worthy of the commitment and effort involved in making its work productive.

\section{APPLICABILITY TO OTHER INSTITUTIONS}

The overarching framework that supported the past three years of focused faculty study groups within the authors' teacher preparation program provides a pathway for program development that is focused on learner outcomes in P-12 schools. While program developers at this institution realize that their immediate focus was on the development of a rigorous teacher preparation program, the ultimate goal was to prepare teachers who would positively impact student learner outcomes in the school setting. In order to accomplish this, a comprehensive and cohesive assessment system was developed which yields qualitative and/or quantitative data, triangulated for validity. The assessments are varied to provide information about a range of issues related to teacher effectiveness (i.e., content knowledge; pedagogical content knowledge; professional and pedagogical knowledge, skills, and dispositions; impact on student learning; others). Program innovations and changes are made based on study of these assessment outcomes. Renaissance Teacher Work Sample Methodology, a widely recognized and exemplary model for teachers' use in designing instruction, measuring impact on student learning, building reflective abilities, and adapting instruction, has figured into this model prominently, providing rich data for faculty to study relevant to teacher candidates' performance in the field. The methodology also requires teachers to plan and deliver instruction based on the needs of each and every learner in the classroom.

The framework for longitudinal faculty study groups provides a blueprint for institutionalizing the change process within teacher preparation programs. Within the framework are rich opportunities for action research, decision making based on pertinent data, and the strengthening of the teacher education/P-12 school partnership as teacher candidates mine their teaching experiences for data that in turn informs the work of the teacher education programs from whence they hail. The relationship to NCATE Standards renders this process of value to institutions wishing to comply with the same.

\section{REFERENCES}

1. Burton, L. (1997). Overcoming the inertia of traditional instruction: Final report on the social work faculty development program at Andrews University. Berrien Springs, MI: Chairs Council, The College of Arts and Sciences, Andrews University. (ERIC Document Reproduction Service No. ED 411722).

2. Delta State University. (2007). Delta State University Bulletin. Cleveland, MS: Author.

3. Garvin, P. (Ed.). (2003). Developing knowledgeable teachers: A framework for standards-based teacher education supported by institutional collaboration. Washington, DC: AACTE Publications.

4. Lang, H. R., \& Evans, D. N. (2006). Models, strategies, and methods for effective teaching. Boston, MA: Pearson.

5. Lave, J. (1988). Cognition in practice: Mind, mathematics, and culture in everyday life. Cambridge: Cambridge University Press.

6. Levine, A. (2006). Educating school teachers. Washington, D.C.: The Education Schools Project.

7. Lick, D. W. (2000). Whole-faculty study groups: Facilitating mentoring for school-wide change. Theory into Practice, 39(1), 43-49. 
8. Maxie, A. (2001). Developing early field experiences in a blended teacher education program; from policy to practice. Teacher Education Quarterly, 28(1), 115-131.

9. Murphy, C. U., \& Lick, D. W. (2006). Whole-faculty study groups: Creating professional learning communities that target student learning. ( $3^{\text {rd }}$ ed.). Thousand Oaks, CA: Corwin Press.

10. National Council for Accreditation of Teacher Education (2002). Professional standards for the accreditation of schools, colleges, and departments of education, 2002 edition. Washington, DC: National Council for Accreditation of Teacher Education.

11. Renaissance Partnership for Improving Teacher Quality. (2002). The Renaissance Partnership for Improving Teacher Quality: Teacher work sample: Performance prompts, teaching process standards, scoring rubrics. Retrieved February 24, 2005, from the University of Northern Illinois, Renaissance Partnership website: http://fp.uni.edu/itq/PDF?files/June 2002promptandrubric.pdf

12. U. S. Department of Education. (2006). A test of leadership: Charting the future of U. S. higher education (U.S. Department of Education Publication No. Ed002591P). Washington, D. C.: Author.

13. Wildman, T. M., Hable, M. P., Preston, M. M., \& Magliaro, S. G. (2000). Faculty study groups: Solving "good problems" through study, reflection, and collaboration. Innovative Higher Education, 24(4), 247263.

\section{NOTES}


NOTES 